Images dans le monde ibérique et ibéricoaméricain

$8 \mid 2015$

L'Histoire et ses récits entre images, fictions et paratextes

\title{
Carta a Luis XIII (1635) : un libelle belliqueux et révérencieux. Quand la marge quévédienne oscille entre guerre et paix...
}

Delphine Hermes

\section{(2) OpenEdition}

\section{Journals}

Édition électronique

URL : http://journals.openedition.org/agedor/503

DOI : 10.4000/agedor.503

ISSN : 2104-3353

Éditeur

Laboratoire LISAA

Référence électronique

Delphine Hermes, "Carta a Luis XIII (1635) : un libelle belliqueux et révérencieux. Quand la marge quévédienne oscille entre guerre et paix... », L'Âge d'or [En ligne], 8 | 2015, mis en ligne le 01 février 2016, consulté le 05 mai 2019. URL : http://journals.openedition.org/agedor/503 ; DOI : 10.4000/ agedor.503 


\title{
Carta a Luis XIII (1635) : un libelle belliqueux et révérencieux. Quand la marge quévédienne oscille entre guerre et paix...
}

\begin{abstract}
Résumé : La marge déploie dans la périphérie du texte des ajouts, ratures et corrections qui viennent éclairer, expliciter ou contredire parfois le bloc central. Le support manuscrit, ou imprimé et amendé par des notes marginales, donne alors à la sphère de la réception tout son sens à plus forte raison quand il s'agit de l'auteur lui-même qui retouche sa production. Dans sa lettre à Louis XIII, Francisco de Quevedo transforme le creuset du texte en une superposition de pensées selon les phases de rédaction et de relecture. Inscrite dans le conflit franco-espagnol, cette lettre dévoile les inflexions idéologiques et personnelles d'un auteur qui répond avec conviction à la déclaration de guerre de 1635 . Toutefois, à l'image du conflit historique et comme en témoigne l'espace liminaire, l'écriture envenimée oscille entre guerre, reproches, diplomatie, ménagement du commanditaire, déférence royale et désir de paix.
\end{abstract}

Mots-clés : Marges - Manuscrits - Variantes - Réception - Herméneutique - Paratexte - Conflits

Resumen: El margen despliega en la periferia del texto añadidos, tachaduras y correcciones que esclarecen, explicitan o, en ocasiones, contradicen el cuerpo central. El soporte manuscrito, o impreso y enmendado por notas marginales, otorga en ese caso a la esfera de la recepción todo su sentido, sobre todo cuando es el propio autor quien retoca su producción. En su letra dirigida a Luis XIII, Francisco de Quevedo transforma el crisol del texto en una superposición de pensamientos de acuerdo a las fases de redacción y de relectura. En el marco del conflicto franco-español, esta carta revela los puntos de inflexión ideológicos y personales de un autor que responde con convicción a la declaración de guerra de 1635. No obstante, a la imagen del conflicto histórico, y como lo manifiesta el espacio preliminar, la escritura enconada oscila entre guerra, reproches, diplomacia, miramientos del valido español, deferencia real y deseo de paz.

Palabras clave: Márgenes - Manuscritos - Variantes - Recepción - Hermenéutica - Paratexto Conflictos

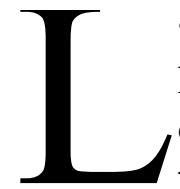

'œuvre polygraphe de Francisco de Quevedo ne cesse d'interroger toute certitude herméneutique tant la base de ses écrits, dont le support autographe a souvent disparu, est soumise à des variantes textuelles et tant son abondante production peut sembler parfois déroutante en termes d'évolutions idéologiques ${ }^{1}$. La Carta a Luis XIII², écrit

\footnotetext{
${ }^{1}$ Citons, parmi les nombreuses études à ce sujet, les articles de Raimundo LIDA, «Sobre Quevedo y su voluntad de leyenda », Filología, VIII, 3 (1962), p. 273-306 ; d'Antonio GARCÍA BERRIO, «Quevedo: de sus almas a su alma », Anales de la Universidad de Murcia, 26, 1 (1967-1968), p. 85-167 ; de Josette RIANDIÈRE LA ROCHE, «Quevedo en su vida y en su mundo: unas claves de lectura», Anthropos Extra, 6 (2001), p. 14-22, d'Alfonso REY, " La construcción crítica de un Quevedo reaccionario», Bulletin hispanique, 112-2 (2010), [en ligne <http://bulletinhispanique.revues.org/1235>, dernière consultation : le 15/09/2014]

2 Le texte intitulé Carta al Serenísimo, muy alto y muy poderoso Luis XIII, Rey Cristianísimo de Francia comprend de nombreuses éditions, dont l'édition princeps conservée à la BNE (édition de la veuve d'Alonso Martín, Madrid, 1635, en ligne sur Biblioteca digital hispánica, U 5059) et le fac-similé de Saragosse. Voir la génétique du texte dans
} 
circonstanciel de propagande, ne déroge pas à ce principe dans la mesure où ces quelques pages répondent à un contexte de convulsions historico-politiques, d'enjeu confessionnel et de réponse à la déclaration de guerre de la France (1635). Aussi la critique connait-elle plusieurs versions de ce texte, que l'on pourrait qualifier d'« écrit-mosaïque ». Il se compose de corrections, de gloses, de notes et d'additions qui se déclinent dans les marges et ratures de manuscrits ou d'imprimés de l'époque, proposant, ici et là, des postures quévédiennes tantôt conciliantes, tantôt intransigeantes envers l'État voisin. Ainsi, l'intérêt de l'œuvre étudiée émerge de la possibilité de réunir au travers d'un même texte, par des retouches scripturales successives, les facettes de Quevedo, auteur, lecteur, traducteur et philologue $e^{3}$.

Aborder cet écrit par le questionnement de la marge permet de ne pas saisir la finitude d'un texte qui par essence n'y atteint jamais, au regard de la perte des pages autographes, mais offre l'opportunité de concevoir les mailles d'une production parfois perçue comme décousue et peu élaborée. À cet égard, force est de constater que le contenu original - le centre du texte en opposition avec sa périphérie - gagne en interprétation par l'analyse des interventions marginales apportées a posteriori par l'auteur lui-même. Ses notes attestent, d'une part, le rôle incontournable de la périphérie textuelle ${ }^{4}$ à l'époque moderne et souligne, d'autre part, l'anticipation stratégique d'un écrivain en proie aux desseins patriotiques, aux attentes de la Cour et aux critiques de ses ennemis littéraires.

Un regard contrastif entre les notes auctoriales ultérieures d'un manuscrit ${ }^{5}$ et celles d'une copie imprimée de l'œuvre ${ }^{6}$ dévoile une stratification de positionnements quévédiens, apparemment contradictoires, selon les phases d'écriture mais qui s'orientent paradoxalement vers une même visée idéologique de l'auteur. La marge se met ici au service de la rhétorique de la persuasion/séduction ${ }^{7}$ qui oscille entre «douceurs et outrages $»^{8}$. Dans la guerre de libelles de 1635, l'appel aux armes quévédien s'inscrit dans une problématique stratégique non exempte d'une attitude respectueuse, parfois même non belliqueuse. Une telle propension quévédienne se caractérise pourtant par un fondement immuable : la distinction réalisée entre la figure sacrée du

l'article de María Soledad ARREDONDO, « Notas para una edición de la Carta a Luis XIII de Quevedo », in Edición $y$ anotación de textos en el Siglo de Oro, Ignacio Arellano AYUSO et Jesús CAÑEDO [coord.], Navarra, Universidad de Navarra, Servicio de Publicaciones, 1987, p. 13-22.

3 EGUÍA ARMENTEROS, Diana, "Tres ejemplos de intertextualidad en la composición escrita de Quevedo », Manuscrt.Cao, 13 [article en ligne <http://www.edobne.com/manuscrtcao/wp-content/uploads/intertextualidadquevedo-bandw.pdf $>$, dernière consultation : le 22/08/2014].

${ }^{4}$ Nous entendrons par «périphérie textuelle » l'ensemble paratextuel du péritexte et de l'épitexte (« est épitexte tout élément paratextuel qui ne se trouve pas matériellement annexé au texte dans le même volume, mais qui circule en quelque sorte à l'air libre ») pour reprendre les termes de Gérard GENET'TE, Senils, Paris, Seuil, 1987, p. 11 et p. 316 pour la définition de l'épitexte.

${ }^{5}$ BNE, Ms. 6156, folios 47-53.

${ }^{6}$ Real Academia de la Historia, Ms. 9-879. Les annotations holographes de Quevedo y ont été répertoriées et explicitées par Carmen PERAITA HUERTA, «Mapas de lectura, diálogos con los textos: la Carta al rey Luis XIII y las anotaciones en el ejemplar de la Utopía de Quevedo », La Perinola 8 (2004), p. 321-341.

${ }^{7}$ Lire, à ce sujet, l'article de Mercedes BLANCO qui explicite comment la raison d'État est tributaire d'un arte de prudencia et d'un art d'écrire, "Arte de ingenio et Arte de prudencia: le conceptisme dans la pensée politique du XVII siècle », Mélanges de la Casa de Velárquez, t. 23, 1987, p. 355-386. Le conceptisme se loge ainsi dans une évolution de l'histoire des mentalités : «Ainsi l'écrivain conceptiste se sent à l'étroit dans la vieille rhétorique fondée sur la persuasion et qui permet tout au plus des discours apologétiques [...]. Une réflexion même sommaire sur les mécanismes du maintien et de l'acquisition de pouvoir en régime d'absolutisme monarchique, à une époque où les identités nationales se constituent sur le fond d'un conflit permanent, le mène à constater que le jeu du pouvoir a des fondements irrationnels, et que les procédés de persuasion ont peu de poids face aux procédés de séduction. »

${ }^{8}$ Expression de Juan de JÁUREGUI venant discréditer le pamphlet quévédien, extraite du Memorial al Rey nuestro Señor (1635) et citée par Juan MATAS CABALLERO, "Quevedo y Jáuregui frente a frente », in Sobre Quevedo y su época, Homenaje a Jesús Sepúlveda, Felipe B. PEDRAZA JIMÉNEZ et Elena E. MARCELLO [éds.], Cuenca, Ediciones de la Universidad de Castilla-La Mancha, 2007, p. 151-184. Lire également la longue note de bas de page de Luis ASTRANA MARÍN, Epistolario completo de don Francisco de Quevedo, Madrid, Editorial Reus, 1946, p. 289 (cf. lettre numérotée CL). 
prince, qui appelle à la déférence, et les principes d'État(s), qui tendent vers un pragmatisme certain.

Il s'agira donc, dans un premier temps, d'analyser le processus de fabrication d'un texte brûlant de l'actualité politique de l'époque, et par là même des lignes sillonnées de reproches. Entre ratures, notes auctoriales imprégnées d'inflexions sémantiques sur un manuscrit de la version originale, le texte s'est ainsi progressivement paré d'une patine plus cordiale ou de desseins politiques orientés, dévoilant le désir quévédien de faire partie intégrante du destin de l'Espagne. Finalement, les notes de Quevedo sur un imprimé de cette lettre et la mention de la publication au sein d'un épitexte épistolaire dessinent l'enjeu de la réception et les postures idéologiques d'un auteur véritablement enrôlé dans la défense de sa Nation.

D'une écriture réactionnelle et réactionnaire, nourrie par la colère et la vengeance, se détachent toutefois quelques notes liminaires qui viennent modérer la tension quévédienne première. En effet, la véhémence de l'auteur à l'encontre du monarque français, représentant de droit divin, s'amenuise tandis que d'autres annotations ultérieures prennent également soin de contenter le commanditaire de cet écrit: le favori du roi espagnol, Olivares. Les marges quévédiennes seront donc sujettes à une étude sociocritique, comprenant les finalités du processus d'élaboration du texte et sa projection lectoriale saisie au travers du prisme de données socio-politiques. De fait, chacun de ces axes module, tout autant que les cibles (lexique de la guerre employé délibérément ici par mimétisme) contre lesquelles s'envenime la plume acerbe quévédienne, le contenu textuel et sa périphérie.

\section{Une encre qui s'envenime et des ratures comme preuves}

C'est à Jover ${ }^{10}$ que l'on doit l'étude minutieuse de la guerre de propagande à laquelle se livrèrent l'Espagne et la France lors de la guerre de Trente Ans et plus précisément au cours de l'année-charnière $1635^{11}$, date de la déclaration de guerre. Le conflit, annoncé le 19 mai et dont le manifeste fut paraphé le 6 juin par le monarque français, connut alors un nouvel affrontement militaire et littéraire entre les deux nations, mettant parallèlement en exergue la rivalité entre les deux favoris, Richelieu et Olivares ${ }^{12}$. Chacun constitua une équipe de libellistes à sa solde. Le Comte-Duc désigna une junta d'auteurs afin de riposter aux menaces et accusations françaises ${ }^{13}$ et ne put qu'avoir recours, entre autres, à la plume de Quevedo, qui évoluait dans les cercles du Palais, auteur obnubilé par les actualités politiques de son temps ${ }^{14}$ et connu pour ses frasques et son orageuse réputation. L'écrivain signa ainsi le 12 juillet 1635 la Carta a Luis XIII où s'entremêlent deux motifs : la réponse aux hostilités françaises et une quête de vengeance, par

\footnotetext{
9 Cet exemplaire aurait appartenu à Quevedo, cf. Diccionario filológico de literatura española, coordonné par Delia GAVELA et Pedro C. ROJO ALIQUE, et sous la direction de Pablo JAURALDE POU, Madrid, Castalia, II, 2010.

${ }^{10}$ JOVER ZAMORA, José María, 1635. Historia de una polémica y semblanza de una generación, Madrid, Consejo Superior de Investigaciones Científicas, 1949.

${ }^{11}$ De fait, un congrès qui s'est tenu les 28 et 29 octobre 2010 a porté uniquement sur cette année précise. Intitulé «1635. Literatura e historia en torno a una crisis », la coordination scientifique de cette manifestation co-organisée par Universidad de Santiago de Compostela, École des hautes études hispaniques et ibériques (Casa de Velázquez, Madrid) a été assurée par Alfonso Rey Álvarez et María José Alonso Veloso.

12 REY ÁLVAREZ, Alfonso, Obras completas en prosa de Quevedo, Madrid, Castalia, vol. III, 2005, note 27, p. 265.

${ }_{13}$ On notera également la participation du diplomate Saavedra Fajardo, du père Bautista, de l'historiographe Pellicer, et d'écrivains comme Jáuregui, Guillén de la Carrera, Céspedes y Meneses dans cette levée de boucliers contre les accusations françaises.

14 ETTINGHAUSEN, Henry, «Ideología intergenérica : la obra circunstancial de Quevedo », in Estudios sobre Quevedo. Quevedo desde Santiago entre dos aniversarios, Santiago FERNÁNDEZ MOSQUERA (coord.), Santiago de Compostela, Servicio de Publicaciones de la Universidad de Santiago de Compostela, 1995, p. 225-259.
} 
l'entremise royale, à l'issue des exactions commises lors de l'un des premiers épisodes de la guerre de Trente Ans, à savoir le saccage de la ville belge de Tirlemont sous le commandement du maréchal de Châtillon. Quevedo décrivit, dans la lettre ${ }^{15}$, le ravage de la ville par les troupes d'huguenots. La première mention de cette exaction intervient après une longue énumération de méfaits français (la collaboration avec le roi de Suède, les conflits sur le sol italien, la suppression des terres du duc de Lorraine) apparemment mineurs, aux yeux de Quevedo, en comparaison avec ce tragique événement :

Nada de todo esto hirió mi ánimo y arrebató mi pluma, encaminándola con fervor animoso a vuestro servicio. Apoderse, empero de mi espíritu el saco de Mos de Xatillon, vuestro General en Tillimon. Estando parlamentando con la villa, saqueó el lugar, degolló la gente, forzó las vírgenes, y las monjas consagradas a Dios, quemó los templos, y conventos, y muchas religiosas, rompió las imágenes, y profanó los vasos Sacrosantos. Últimamente joh señor!, ¿direlo? Quanquam animus meminisse horret, luctuque refugit. "Si bien se espanta la alma de acordarse y con dolor rehúsa la memoria", dio en las hostias consagradas a sus caballos el santisímo Sacramento, que por excelencia se llama Eucaristía ${ }^{16}$.

Deux objectifs tissent ainsi la motivation de l'écrit quévédien : une participation active à la campagne propagandistique anti-française et la dénonciation du saccage de la ville de Tirlemont où les symboles catholiques ont été profanés. Le contexte de la rivalité catholiques/protestants vient complexifier le heurt idéologique France-Espagne. En effet, la guerre dite «des deux Couronnes », opposant deux beaux-frères, Louis XIII et Philippe IV, ébranla la chrétienté car l'un était le Roi très chrétien - titre repris d'ailleurs dans le titre de la lettre quévédienne - et l'autre le Roi catholique $^{17}$. Aux guerres de religion s'est adjoint l'enjeu d'une Europe naissante où chaque État souhaitait se positionner, et où précisément Richelieu tentait de canaliser les prétentions des Habsbourg. Quevedo, animé par une conviction catholique, souligne maintes fois, dans cette lettre, le paradoxe de l'État français enclin à réprimer les protestants sur son propre sol mais susceptible de les inciter à s'affirmer dans le Nord de l'Europe tant il est conscient de la séparation théorique entre raison d'État et la majesté divine ${ }^{18}$. Alors que l'unité de la Nation se cristallise dans la figure du monarque absolu, «l'État juxtapose à cet ordre un ordre universel, mais immanent, dont l'origine est peut-être divine, mais dont la structure et la définition sont entièrement humaines. L'État se doit d'être le plus puissant possible, donc le plus vaste, le plus uni, le plus riche, le plus redoutable $»^{19}$. Dans cette coexistence d’unités ont émergé les inimitiés et les guerres d'une Europe naissante.

Quand Quevedo se plaît à souligner à l'intention du roi de France combien la nation de ce dernier compte des ennemis tout à la fois intérieurs et extérieurs, il reprend une citation de Lucain dont il inverse les termes, désireux de faire allusion, de façon spirituelle et méchante ${ }^{20}$, à la

\footnotetext{
${ }^{15}$ Les citations ici utilisées sont des extraits - que nous avons modernisés - du manuscrit 6156, complétés au besoin par la version, plus complète, de la lettre issue de l'édition de 1635, Madrid, viuda de Alonso Martín, [En ligne : $<$ www.bne.es>, dernière consultation : le 09/09/2014].

${ }^{16}$ BNE, Ms. 6156, folio 50.

17 DEVĖZE, Michel, «1635- Le heurt idéologique franco-espagnol», in Les relations franco-hispaniques, Paris, Bibliothèque Nationale, 1971, tome 1, p. 23-39.

18 On en voudra pour preuve le passage suivant qui se trouve dans la princeps : « Por esto, con sospechoso cuidado, cautelan vuestros ministros el tratado de la religión, con hacer que a la guerra (que la hacen armando la herejía contra ella y desarmándola) preceda mal disimulada la cláusula, con todas sus letras hipócrita, de que siempre será amparada la verdad católica. Siendo así que, por la propia razón que cuando la infancia de vuestra majestad, quitando las fuerzas a la herejía, la oprimió, hoy, que da fuerzas a los herejes, ensalza la herejía, y aquella promesa, "siempre será amparada la fe católica", se muestra desconfiada de él, cuando en lo por venir ».

${ }^{19}$ BLANCO, Mercedes, «Arte de ingenio », art. cit, p. 356.

${ }^{20}$ La reprise du vers latin a été source de critiques de la part de Jáuregui à l'encontre de Quevedo qui a inversé les propos de Lucain. Il semble toutefois très probable que Quevedo ne traduise pas littéralement la citation dans le cadre d'une tournure conceptiste afin de souligner la menace intérieure qui couve en France (cf. Alfred MORELFATIO, «Compte-rendu de lecture », Bulletin Hispanique, 10, p. 137-139).
} 
menace hérétique, protestante, qui assiège la France. Quevedo peut ainsi s'exclamer: "joh Francia! In te verte manus, nondum tibi defuit hostis. Vuelve sangrientas contra ti las manos, aun a ti no te falta en ti enemigo. No te faltan, no, dentro de ti misma, cuando dentro de ti tiene Dios tantos enemigos $»^{21}$, tant la France qu'il fustige possède, tout comme lui d'ailleurs, des adversaires extérieurs et tout proches. Il nous faudra identifier les cibles françaises - un cas seulement, parmi d'autres, de menaces extérieures - pointées par l'auteur selon leurs divers statuts : l'entité globale de l'État français qui concurrence l'Empire des Habsbourg, la personne même du cardinal Richelieu, les troupes françaises, le sacrilège maréchal de Châtillon et le peuple français souvent décrit de façon stéréotypée. Mais Quevedo subit également une foule d'inimitiés tant littéraires que politiques $^{22}$. Si ses ennemis littéraires l'ont affronté par des écrits ou des obligations de censure, les plus hautes instances lui infligèrent, pour leur part, non pas moins que l'exil et des emprisonnements.

Confronté à ces réalités, «l'homme du Diable ou l'homme de Dieu» $»^{23}$ est soumis à différents facteurs qui modulent le contenu de ses écrits : le rôle d'écrivain en quête de mécénat et de protection, l'originalité scripturale pour parfaire sa réputation littéraire, une conscience politique exacerbée ${ }^{24}$, l'appréhension des censeurs, et enfin, le statut de sujet et de courtisan ${ }^{25}$ dans le cadre d'une monarchie confessionnelle en période de crise $^{26}$. Aussi, ces pages contiennent-elles, d'abord, la réaction envenimée d'un auteur fortement impliqué dans la conservation de l'État espagnol. Quevedo recourt à une instrumentalisation générique, thématique, religieuse, circonstancielle de la littérature à des fins extralittéraires, pour ne pas subir la politique mais en faire partie intégrante ${ }^{27 .}$

En dépit d'une forme d'échange épistolaire, cette lettre ouverte à Louis XIII dépasse le cadre privé et appartient à la catégorie de production littéraire circonstancielle. Certaines corrections auctoriales permettent d'ailleurs un accès à un texte premier plus incisif encore. Il est intéressant de remarquer que la plupart des œuvres quévédiennes étaient vouées à un processus de transmission essentiellement manuscrit ou de publication tardive ${ }^{28}$ alors que cette lettre commanditée par l'idéologie dominante de la Couronne espagnole était conçue pour une édition immédiate comme en témoigne le délai si prompt entre la déclaration de guerre officielle (juin 1635) et la date de la signature du pamphlet quévédien (12 juillet 1635).

La présence de ratures quévédiennes sur la version originale laisse présager un premier jet rapide, que l'auteur s'est efforcé de policer par la suite. Ce sont bel et bien les traces d'une pensée plus sévère envers la France qui se dégagent par-dessous les ratures et parfois dans les corrections de la marge. En effet, à en juger par le texte de la version originale (Ms 6156), Quevedo a repris, avant la publication, certains passages qui reflètent une écriture d'abord plus réactionnelle tant le contenu de ces passages barrés ou raturés renferme une attaque initiale directement dirigée contre le souverain français. Dans la marge du folio 50 , après le récit du saccage de la ville de Tilermont, déborde une proposition, fruit de la plume de Quevedo, qui est celle désormais utilisée par les

\footnotetext{
${ }^{21}$ BNE, Ms. 6156, folio 50.

22 SERRANO PONCELA, Segundo, « Los enemigos de Quevedo », Anuario de Filología, II-III (1963-64), p. $235-251$.

${ }^{23}$ BOUVIER, René, Préface de L'Heure de tous on la fortune raisonnable, traduction de Jean Camp, Paris, Nouvelles Editions Latines, 1934, p. 10.

${ }^{24}$ Ce sujet est déjà amplement traité. L'article de Victoriano RONCERO LÓPEZ, «Quevedo y la ideología política barroca ", in Sobre Quevedo y su época... op. cit., p. 89-105, précise notamment l'intérêt de Quevedo pour l'Espagne et la prédominance de sa vision de la figure du Roi.

25 JAURALDE POU, Pablo, Francisco de Quevedo (1580-1645), Madrid, Editorial Castalia, 1999. Lire également du même auteur : "La familia de Quevedo ", in Estudios sobre Quevedo. Quevedo desde Santiago entre dos aniversarios, op. cit., p. 45-67.

${ }^{26}$ Lire, par exemple, les pages de José ANTONIO MARAVALL, "Sobre el pensamiento social y político de Quevedo (una revisión)», in Homenaje a Quevedo, Víctor GARCÍA DE LA CONCHA (coord.), Salamanque, Université de Salamanque, 1982, p. 69-131.

27 MARTÍNEZ GUTIÉRREZ, Carlos, La espada, el rayo y la pluma. Quevedo y los campos literario y de poder, West Lafayette, Indiana, Purdue University Press, 2005, p. 218.

${ }^{28}$ JAURALDE POU, P., « La transmisión de la obra de Quevedo », in Homenaje a Quevedo, op. cit., p. 163-172.
} 
diverses éditions : «¿Cómo, siendo vos cristianísimo, permitiréis lo que los calvinistas y luteranos detestan, y lo que Satanás no ha podido obrar con otras armas que con las de Xatillon ?»²9. Toutefois, le texte premier fait montre d'un reproche adressé au destinataire, c'est-à-dire Louis XIII : «y lo que Satanás no ha podido obrar con otras armas que con las vuestras? ».

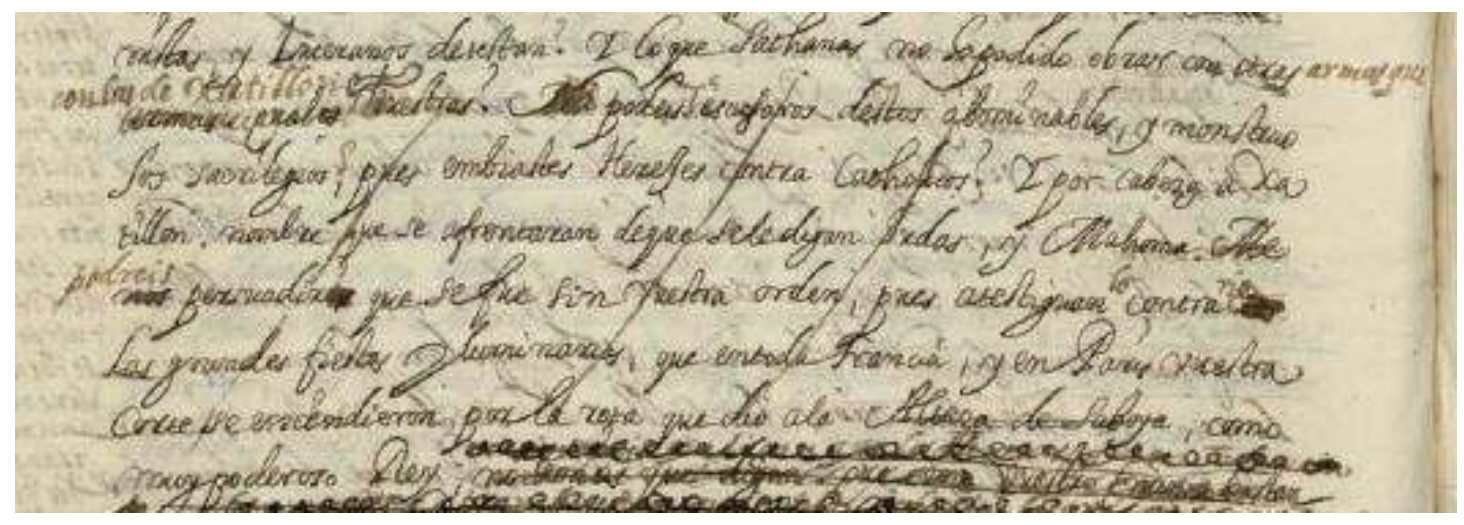

1. Illustration des interventions holographes quévédiennes (BNE, Ms. 6156, folio 50).

De même, les lignes suivantes, qui reprennent les festivités relatives à la victoire de Châtillon, sont barrées par des traits obliques et sont remplacées par une note adjointe au manuscrit.

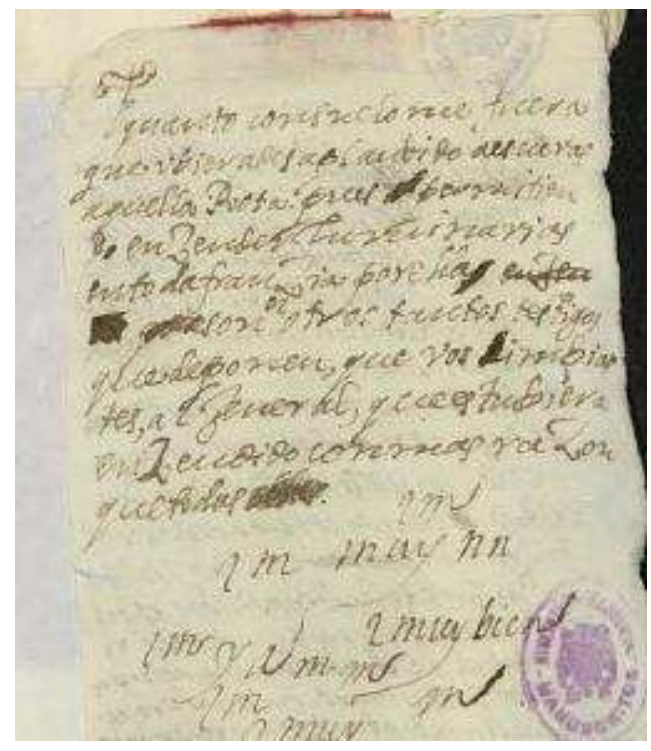

2. Note libre qui vient se substituer au passage raturé de lillustration antérieure (BNE, Ms. 6156).

Le texte ici ajouté indique: «¡Cuánto consuelo me fuera, que hubiérades aplaudido a oscuras aquella rota, pues permitiendo encender luminarias en toda Francia por ella son hoy otros tantos testigos que deponen que vos enviastes al general, que estuviera encendido con más razón que todas! $»^{30}$. Ce passage n'est ainsi qu'un simple regret évoqué par Quevedo qui détourne la commémoration des réjouissances par l'éventuel devoir de mémoire des participants devenus

${ }^{29}$ BNE, Ms. 6156, folio 50.

${ }^{30}$ Ibid. 
témoins et acteurs des sacrilèges commis. La dérivation de encender permet une tournure conceptiste qui se joue tout à la fois de la référence à la combustion des torches utilisées pour la célébration et de l'allusion à la colère qu'aurait dû ressentir le Général Châtillon si la célébration de la défaite (énonciation antithétique qui marque le parti pris quévédien) avait été telle. Or, le texte original, barré ( $c f$. illustration 1), mentionne pour sa part la culpabilité démontrée du monarque français de façon plus patente :

$\mathrm{Ni}$ podéis excusaros de estos abominables y monstruosos sacrilegios, pues enviastes Herejes contra Católicos. Y por cabeza a Châtillon, nombre que se afrentaran a que se le digan Judas y Mahoma. Me podréis persuadir que se fue sin vuestra orden, pues atestiguan lo contrario las grandes fiestas y luminarias, que en toda Francia y en París vuestra Corte se encendieron por la rota que dio a la Alteza de Saboya ${ }^{31}$.

Cette référence à la bataille d'Avin (20 mai 1635) soulignait le rôle de Thomas de Savoie et indirectement son alliance avec l'Espagne, ce que l'auteur supprima par la suite. La diabolisation de Châtillon restait de mise mais les reproches religieux et militaires à l'encontre de Louis XIII ont été passés sous silence. Nous pouvons ainsi conclure que ces premières ratures substituées par un contenu moins querelleur envers le roi de France portent encore dans leur sillage les traces d'une écriture immédiate, acerbe, d'un auteur espagnol blessé par le souvenir d'une défaite militaire toute récente. D'aucuns affirment même que parmi les collaborateurs à la campagne propagandistique mandatée par Olivares : "seul Quevedo s'en prend directement à Louis XIII ; on le sent lui-même très affecté, mais certains ont dit que c'était Philippe IV qui s'exprimait pas sa bouche $»^{32}$. Ce sont l'élan patriotique et le désir d'une Espagne impériale qui transparaissent dans la trame du texte premier que Quevedo, à des fins stratégiques, s'est efforcé d'adoucir dans sa tâche de lecteur/auteur.

\section{Un paratexte entre « douceurs et outrages »}

Cette étude génétique du texte Carta a Luis XIII permet de défaire deux moments d'écriture, l'un en proie à l'actualité, occulté derrière les ratures et le second plus apaisé, dévoilant une déférence quévédienne vis-à-vis du monarque français. Les retouches successives de l'auteur lui-même sur le manuscrit et sur l'imprimé mettent en valeur le rôle de l'écrivain qui cherche à maitriser les effets d'un texte empli de finalités politico-religieuses. Notons, à cet effet, que la culture de l'ère baroque répondant aux desseins de l'idéologie dominante vise à insuffler des normes de conduite aux hommes dans un souci de préservation des principes politiques du moment $^{33}$, même si certains écrits quévédiens nourrissent ici et là un anticonformisme qui participa à sceller la réputation d'un homme audacieux et provocateur ${ }^{34}$. Parallèlement, la figure d'un Quevedo humaniste, qui annote, glose les textes d'autres et continue de reprendre les siens, fait de la littérature un espace de réécriture ${ }^{35}$ où le texte est sans cesse renouvelé par les apports

\footnotetext{
${ }^{31} \mathrm{Ibid}$. Nous avons conservé le terme barré par l'auteur lui-même.

${ }^{32}$ DEVĖZE, Michel, 1635..., op. cit., p. 34.

${ }^{33}$ MARAVALL, José Antonio, La cultura del barroco, Barcelona, Editorial Ariel, 1998, p. 132.

${ }_{34}$ Raimundo LIDA remarque ici la facette conservatrice et patriote d'un auteur offensé : «El orgullo y la gravedad hispanas se manifiestan en la Carta de Quevedo, que renuncia en este opúsculo a su personalidad satírica para lograr una obra que enaltezca a los españoles y los embravezca contra los franceses », in Prosas de Quevedo, Ana Prieto (éd.), Barcelona, Editorial Crítica, 1981.

${ }^{35}$ CAYUELA, Anne, «De reescritores y reescrituras: teoría y práctica de la reescritura en los paratextos del Siglo de Oro », Criticón, 79 (2000), p. 37-46.
} 
des marginalia. Le courant humaniste ${ }^{36}$ rehaussé par la notion d'auteur qui émergea au XVII siècle $^{37}$ fait prendre conscience des enjeux de l’activité scripturale et du désir toujours plus grand d'influencer les lecteurs, ce qui entre en consonance avec le genre ici utilisé : un pamphlet qui, sous allure de lettre, semble jouer entre complicité et provocation. Dans ce même ordre d'idées, le texte cherche tantôt à gagner les faveurs du destinataire, Louis XIII, tantôt à ruiner les prétentions françaises. Cette alternance de contenu qui peut perturber le lecteur est, de surcroit, démultipliée par une enfilade de citations, d'exemples d'actualités et de références lointaines qui finissent par délivrer une sensation de composition morcelée. La lettre est ainsi jalonnée de citations classiques et d'autorités (la Bible, un proverbe grec, Polybe, Lucain, Jules César, Cicéron...) et de la paraphrase, que nous traiterons plus avant, d'un fragment de l'Utopie de Thomas More. La visibilité des notes conditionnées comme ajouts sur le manuscrit original soustend une confection argumentaire non conçue en un seul mouvement de pensée cohérent et unitaire mais davantage comme un socle primaire que l'auteur a fait évoluer au gré de ses relectures, de ses recherches érudites et de phases temporelles distinctes. La lettre à Louis XIII, cet écrit circonstanciel inspiré de faits concrets et dévolus à la défense de l'Espagne ${ }^{38}$, permet de déceler, par le biais de la stratification des notes marginales, la position idéologique de l'écrivain en 1635. Celui-ci quête dans les valeurs classiques, teintées d'atemporalité, une démonstration de la suprématie espagnole et de l'offense terrible commise par les troupes françaises dans cette ville belge contre la majesté divine. La critique émet deux avis antagonistes sur l'estimation littéraire de ce texte : un écrit épars ponctué d'anachronismes ${ }^{39}$ ou, au contraire, un texte savamment élaboré par un auteur ayant pris soin de convoquer un lourd arsenal intertextuel qui s'immisce avec brio dans une réponse circonstancielle ${ }^{40}$. Ce texte ne laisse donc pas ses lecteurs unanimes d'autant que la position quévédienne envers la France peut sembler parfois ambiguë. Mais il faut remarquer que l'expéditeur de la lettre distingue deux entités qui lui sont par définition adverses : l'autorité royale française et tout ce qui lui est afférent (troupes, généraux, conseillers, etc.). Les attaques menées contre le souverain sont, en définitive, soit reliées directement à l'un de ses ministres ou militaires, soit dirigées contre la nature humaine, essence de chaque roi, mais n'entame en rien la notion royale qui demeure intouchable.

\footnotetext{
36 Pour approfondir la relation quévédienne à l'humanisme, cf. GENDREAU-MASSALOUX, Michèle, Héritage et création: Recherches sur l'humanisme de Quevedo, Lille-Paris, Reproduction des thèses, Université de Lille III, Librairie Honoré Champion, 1977. Lire également PERAITA HUERTA, Carmen, "Comercio de difuntos, ocio fatigoso de los estudios : libros y prácticas lectoras de Quevedo », La Perinola, 7 (2003), p. 271-295.

${ }^{37}$ CAYUELA, Anne, Le paratexte au Siècle d'or, Paris, Droz, 1996, p. 139.

${ }^{38}$ ETTINGHAUSEN, Henry, «Ideología intergenérica : la obra circunstancial de Quevedo », art. cit., p. 234.

${ }^{39}$ JAURALDE POU, Pablo, Francisco de Quevedo..., op.cit., p. 694, estime ainsi que « se trata de uno de los textos más espesos y menos afortunados de Quevedo, que no parece haberlo elaborado demasiado - a pesar de las apostillas autógrafas del manuscrito de la Biblioteca Nacional». María Soledad ARREDONDO, «El diamante en el anillo : ensayismo filosófico en Quevedo »Compás de Letras, 5 (1994), p. 145-162, mentionne un texte torturé construit selon une série d'arguments sans lien. Quant à Jáuregui, contemporain et rival de Quevedo, fâché de ne pas avoir été officiellement convié au sein de la junte littéraire de défense de l'Espagne, il contredit nombre des points du texte, depuis des usages lexicaux non appropriés, le style jusqu'aux arguments stéréotypés et anachroniques ( $c f$. MATAS CABALLERO, Juan, «Quevedo y Jáuregui frente a frente », art. cit., plus précisément les pages 169-181).

${ }^{40}$ VIVAR, Francisco, Quevedo y su España imaginada, Madrid, Visor Libros, 2002, p. 152, souligne, quant à lui, l’intérêt historiographique de cette lettre qui présente un portrait en parallèle de chacun des monarques de l'époque. María Soledad ARREDONDO, «Notas para una edición...», art. cit., p. 14, considère pour sa part que « el autor ha sabido conjugar el dato histórico, con una amplia erudición y un uso de la retórica que convierten la obra en una pieza artística [...] Los asertos de Quevedo se basan en autoridades históricas, religiosas y políticas, que maneja hábilmente para lograr sus propósitos ». Dans ce même ordre d'idées, Alfonso REY, dans son introduction au troisième volume de Obras en prosa de Quevedo, p. L, affirme que «Las citas clásicas se acomodan a situaciones contemporáneas saltando tiempos y espacios [...] La Carta a Luis XIII es una digna muestra de libelo político, género tan cultivado en la Europa de entonces ». Parallèlement, Raimundo LIDA, Prosas de Quevedo, op. cit., p. 96, souligne l'habile conception d'un texte capable d'uniformiser sur un même plan d'intemporalité des écrits classiques appliqués à des données historicogéographiques contemporaines à Quevedo : «Los personajes salen de las páginas de los viejos libros gesticulando y clamando, para apoyar el celo patriótico del moderno escritor».
} 
Quant à Jáuregui, il reprocha par exemple à Quevedo la généralisation des critiques royales (dont il n'exclut guère Philippe IV). Il faut penser que l'auteur fit seulement part d'une réflexion morale sur la conduite ambitieuse des rois, sans pour autant discréditer Louis XIII ni même écarter la figure de son propre souverain. On peut ainsi lire : «Esas acciones son de moderada hostilidad, y a los reyes persuade a que las ejecuten, o la pretensión o el odio, tal vez el orgullo y las más la ambición codiciosa de crecerse a costa de sus vecinos, lo que honestan los pretextos inventados $»^{41}$. À l'inverse, quand il s'agit de faire mention du monarque en qualité de détenteur du pouvoir divin, l'auteur se montre chaque fois révérencieux ${ }^{42}$, voire obséquieux selon Jáuregui. La lettre commence ainsi par un rappel des gloires du roi de France et de sa très illustre généalogie. En revanche, les propos visant Richelieu et Châtillon se chargent d'une tonalité très outrageante. Le ton et le contenu afférents à cette répartition selon les cibles évoquées dans le bloc textuel trouvent écho dans les ajouts à l'intérieur de la marge du manuscrit, lesquels ont tous été retenus dans la princeps. Quevedo insère dans le paratexte du folio 48 une autre éventuelle raison de la fuite vers les Flandres du frère de Louis XIII, Gaston d'Orléans. Cette addition, indiquée dans la marge par un obèle, accuse sans ambages le cardinal Richelieu : " $\mathrm{O}$ a asegurarse de la ambición que en su manifiesto, por el duque de Momaransi, acusó a la eminencia del cardenal, que creciéndola sobre su alteza, le amenazaba $»^{43}$.

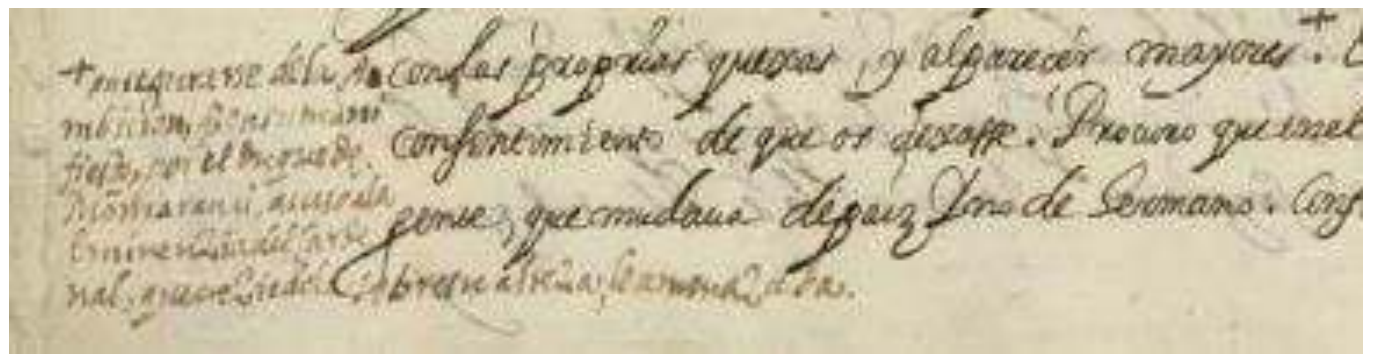

3. Note marginale relevée par un obèle qui poursuit l'accusation contre Richelieu.

Le rôle du favori semble ainsi dépasser les limites de la raison d'État d'après Quevedo au point de briser les liens de la famille royale. L'auteur répond ensuite à un reproche français du Manifeste de déclaration de guerre en établissant un syllogisme par rapport à l'accueil et à la protection que le monarque espagnol a offerts à Marie de Médicis en Flandres ${ }^{44}$. Il se sert, dans la marge, d'une hypothèse a contrario (« si no amparara el rey... ») pour démontrer la légitimité de cette hospitalité eu égard au statut de caballero du roi, réfutant, au passage, son éventuel statut d'ennemi et appelant le propre souverain de France à juger cet acte royal : «ningún príncipe puede excusarse de asistirlos ». Une inversion de rôles et une mention de l'honneur sont associées à Louis XIII. De même, l'auteur utilise la périphérie du manuscrit pour substituer «tierras » par «señoríos » ${ }^{45}$, connotant, de fait, une possession seigneuriale et la reconnaissance d'autorité, comme le signale encore un obèle. Le terme finalement retenu vient faire écho au dernier passage

\footnotetext{
41 BNE, Ms 6156, folio 49.

${ }^{42} \mathrm{Un}$ ton respectueux envers le monarque français est ainsi très palpable dans cet écrit.

${ }^{43}$ BNE, Ms. 6156, folio 48.

$44 \mathrm{BNE}$, Ms 6156, folio 49 : "Si no amparara el rey mi señor a la majestad de vuestra madre, se quejara de su grandeza todo el mundo, y faltara (lo que no podía ser) a la obligación de caballero, y vos os quejárades entonces con razón; y por esto, si os quejáis (lo que no creo) de que la haya amparado, esta queja sola os puede ser indecente, y aquél sabrá reverenciar vuestra grandeza, que no la creyere. Si dijéredes que asistió a vuestro hermano, yéndose malcontento, juzgadlo, señor, y veréis que no pudo desentenderse de que era vuestro hermano y su cuñado, y que no debió persuadirse era vuestro enemigo; antes debió temer lo fuese suyo, lo que brevemente mostró su alteza, con que granjeó de vuestra majestad acogimiento agradable. Vos podéis permitir que los que os asisten ocasionen fuga a vuestra madre y hermano ; empero ningún príncipe puede excusarse de asistirlos ».

45 BNE, Ms. 6156, folio 48.
} 
de l'œuvre de Thomas More que Quevedo exploite par une exhortation lancée à la France à rejeter tout expansionnisme par le biais d'un conseiller royal qui énonce : «y que el rey no imagine que le conviene pensar en añadirse otros señoríos ${ }^{46}$. L'auteur ajoute également sur le manuscrit original le qualificatif de "gloriosas » ${ }^{47}$ pour décliner la victoire de Louis XIII sur les hérétiques. Nonobstant, les additions qui concernent les troupes françaises, leur commandement ou le premier Ministre dévoilent une tout autre position, qui étaie les opinions selon lesquelles Quevedo a usé d'un ton virulent pour proclamer de dures accusations ${ }^{48}$ contre l'ennemi français. C'est ainsi qu'une autre note dans la marge du folio 49 (cf. illustration 4) suggère un glissement depuis un contenu apologétique jusqu'à une sévère accusation qui invite à laisser penser que les exactions et sacrilèges de Châtillon pourraient effacer les exploits français. La subtilité quévédienne repose sur l'opposition entre une nation par essence très chrétienne (la conquête de Jérusalem) et l'hétérodoxie inscrite dans l'action de donner des hosties consacrées aux chevaux à Tilermont :

Conozco las admirables proezas que en todas las edades que ha vivido el mundo han hecho los franceses con sobrehumano valor. ¿Qué memoria no tienen agradecida a su esfuerzo con la conquista de Jerusalén? No pretendo yo deslucir estas acciones antes pretendo que los franceses no las desluzcan. Pretendo que aquella nación, que tanto sudó por libertar el sepulcro que tres días tuvo en depósito el cuerpo de Cristo, no se desdiga en la fe y degenere, haciendo monumento de su precioso cuerpo y sangre los vientres de sus caballos ${ }^{49}$.

\footnotetext{
46 Ibid., folio 53.

${ }^{47}$ Ibid., folio 52.

${ }^{48}$ DEVĖZE, Michel, 1635..., op. cit., p. 34.

${ }^{49}$ BNE, Ms 6156, folio 49.
} 


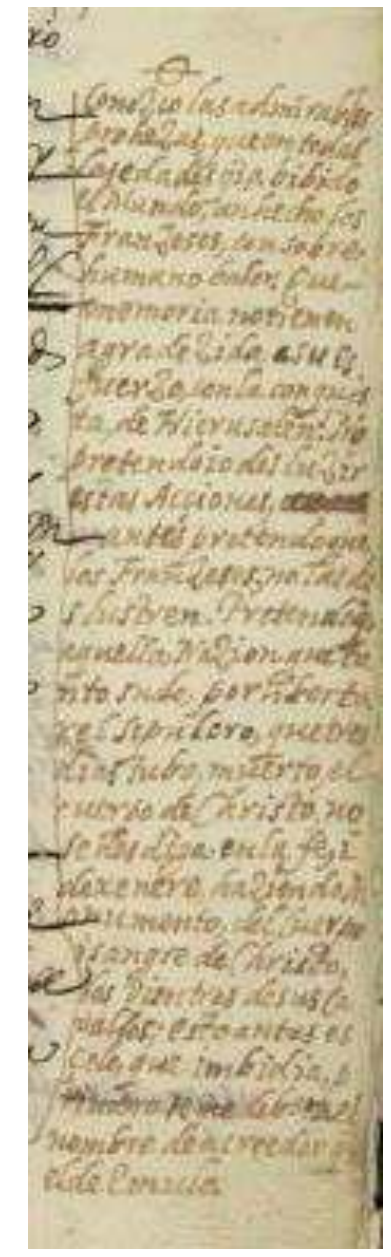

\section{Note quévédienne sous forme de colonne qui concilie compliment et attaque.}

Il ressort ici que la note quévédienne fait état du verbe «deslucir» plutôt que de celui de « escurecer» afin de montrer le renversement entre les prouesses passées et une réalité lointaine à l'époque dorée, désormais discréditée (alors que la princeps reprend le second terme). Les notes du manuscrit étayent un texte qui se veut persuasif et incisif et dont le centre réclame une vengeance à l'encontre de Gaspard III de Coligny (le maréchal Châtillon) et une invitation à craindre Richelieu.

En conclusion, cet écrit de Quevedo apparaît dès lors comme un laboratoire d'écriture où le texte se nourrit d'autorités, d'exemples historiques et d'actualités pour diffuser une visée idéologique déterminée selon laquelle les Français, assimilés ici aux troupes,

demeurent un ennemi, dans le même temps que tout souverain se doit d'être respecté. Le statut de vicaire de Dieu sur terre ou de monarque sacré instaure un indéniable decoro de l'écrivaincourtisan et laisse également émerger une sincère posture de vassal chrétien. Le texte bifurque dès lors entre deux attitudes qui sont renforcées par les annotations marginales: d'une part il s'adoucit quand il traite du roi de France, d'autre part il s'envenime quand il mentionne les conseillers et commandeurs de cette nation ennemie. Ces inflexions de pensées, quoique ici déroutantes, recèlent une même posture idéologique en dépit des stratifications de la périphérie textuelle qui se déclinent en étapes successives mais selon un laps de temps assez bref. La scission entre les cibles traitées par la plume quévédienne est bel et bien là, gravée dans les épaisseurs d'un manuscrit à deux mains, une version originale allographe et les annotations marginales autographes, qui répète un contenu duel dans la dialectique marge/texte. La marge devient donc le lieu d'enjeux intellectuels et se charge d'un aspect technique susceptible de faire évoluer vers davantage de complétude la première version ${ }^{50}$.

\footnotetext{
${ }^{50}$ Sur le rôle évolutif de la marge qui dessine une continuité entre les manuscrits et les imprimés au Siècle d'Or, lire la réflexion de Françoise CRÉMOUX « Marge prescriptive, marge destructrice ? », Pandora, 9, 2009, p. 25-35.
} 


\section{Rôle d'un auteur enrôlé}

La date de 1635 appelle à prendre en compte plusieurs réalités pour discerner les finalités de cet écrit. C'est l'année où éclata le conflit larvé entre la France et l'Espagne et c'est aussi la période où Quevedo, secrétaire de Philippe IV, possédait encore des relations assez étroites avec Olivares $^{51}$. L'auteur se meut donc ici entre la défense de sa nation, son rôle de courtisan, la commande du favori et une réflexion stratégique et politique. D’une part, il s'abandonne avec délectation au souvenir de la défaite française de Pavie ${ }^{52}$, à la bravoure d'une Espagne guerrière ${ }^{53}$ qui contraste avec les faiblesses présumées des soldats français, à la lumière de cette note qui reprend les termes de Jules César : "Y Julio César en el tercero libro de la guerra contesta con Floro : Porque como al acometer la guerra el ánimo de los franceses es pronto, así su mente es blanda y de ninguna manera apta para resistir las calamidades $»^{54}$.

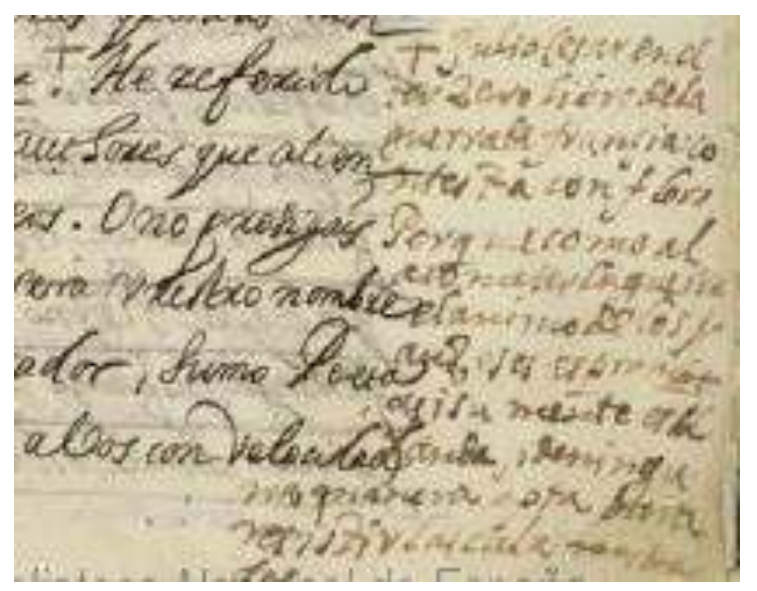

5. Référence marginale intertextuelle qui récuse la vaillance des troupes françaises.

La réponse de l'Espagne à la déclaration de guerre et aux calomnies du Manifeste, qui ne sont autres que les œuvres de ministres ayant usurpé la parole royale ${ }^{55}$, se présente sous la plume de Quevedo comme une réaction légitime car «si la paix consiste pour lui [Louis XIII] à faire à l'Espagne tout le mal qu'il peut, il ne saurait se plaindre que l'Espagne réplique par la guerre $»^{56}$. D'autre part, l'écrivain élabore ce texte comme une paradoxale invitation à la résolution pacifique du conflit ; cette apparente contradiction corrobore l'impression de son détracteur : " esta mezcla de ternezas y ultrajes la define el vulgo con un término que pienso llaman cantaleta ${ }^{57}$. Pour

\footnotetext{
${ }^{51}$ ARREDONDO, María Soledad, «La espada y la pluma contra Francia en el siglo XVII: cartas de Quevedo y Saavedra Fajardo », Criticón, 56 (1992), p. 103-115.

52 BNE, Ms. 6156, folio 52.

Deux passages viennent corroborer explicitement la force militaire de l'Espagne : «No teme España en la batalla al rey de Francia» (Princeps, op.cit.) ; parallèlement, l'explicitation d'une citation de Silius Italicus précise que « os aseguro que los españoles irán a vos con velocidad », BNE, Ms. 6156, folio 52.

$54 \mathrm{BNE}, \mathrm{Ms}$ 6156, folio 52 (note marginale).

55 «El manifiesto que los ministros sobrescribieron magníficamente con vuestro soberano nombre. » (cf. Princeps, op. cit.) Et plus en avant, apparait : « el papel con vuestro nombre impreso », ibid. Quevedo n'identifie pas Louis XIII comme l'auteur du Manifeste mais lui rappelle sa responsabilité royale.

56 PÉREZ, Joseph, La légende noire de l'Espagne, Paris, Fayard, 2009.

${ }^{57}$ JÁUREGUI, J. de, Memorial al Rey nuestro Señor cité par J. MATAS CABALLERO «Quevedo y Jáuregui frente a frente », art. cit., p. 172.
} 
étayer ces deux positions idéologiques, il convient de reprendre, dans un premier temps, la situation infrahistorique d'un auteur, fervent pourfendeur d'une Espagne en crise qui s'affaiblit au rythme de batailles et de guerres incessantes menées sur des fronts divers, tant intérieurs qu'extérieurs, dans un souci de consolidation de la monarchie confessionnelle. C'est ainsi que Quevedo mêla constamment politique et écriture, animé d'un désir de faire perdurer les splendeurs de l'Empire des Habsbourg. D'un point de vue plus personnel, il développa une ambition palaciega $a^{58}$ allant de pair avec l'émergence d'une conscience auctoriale prégnante au $\mathrm{XVII}^{\mathrm{e}}$ siècle. Il suivit, à cet égard, les directives d'Olivares qui prescrivit une réaction antifrançaise et une sublimation de la monarchie espagnole. Aussi, les marges d'un imprimé de la lettre à Louis XIII, qui fut en possession de Quevedo, mettent en exergue un rejet de la nation voisine et la notion de trahison à la différence d'un centre textuel qui comporte des rappels de collaborations, d'alliances et de destin chrétien commun. Trois notes holographes viennent ainsi jalonner l'imprimé ${ }^{59}$ : l'une purement corrective pour amender l'oubli d'une citation latine incomplète, les deux autres notes pour développer une projection réflexive sur le contenu du centre textuel. En effet, aux côtés du nom du duc de Lorraine, Quevedo ajoute une citation de Cicéron, laquelle est totalement absente du manuscrit 6156, version originale du texte. On peut ainsi lire dans la marge : «Cicero. Pro Roscio. Perditissimi igitur est hominis fallere eum, qui lesus non esset nisi credidisset. Es de hombre perdidissimo engañar a aquel, que no fuera ofendido, si no creiera $»^{60}$.

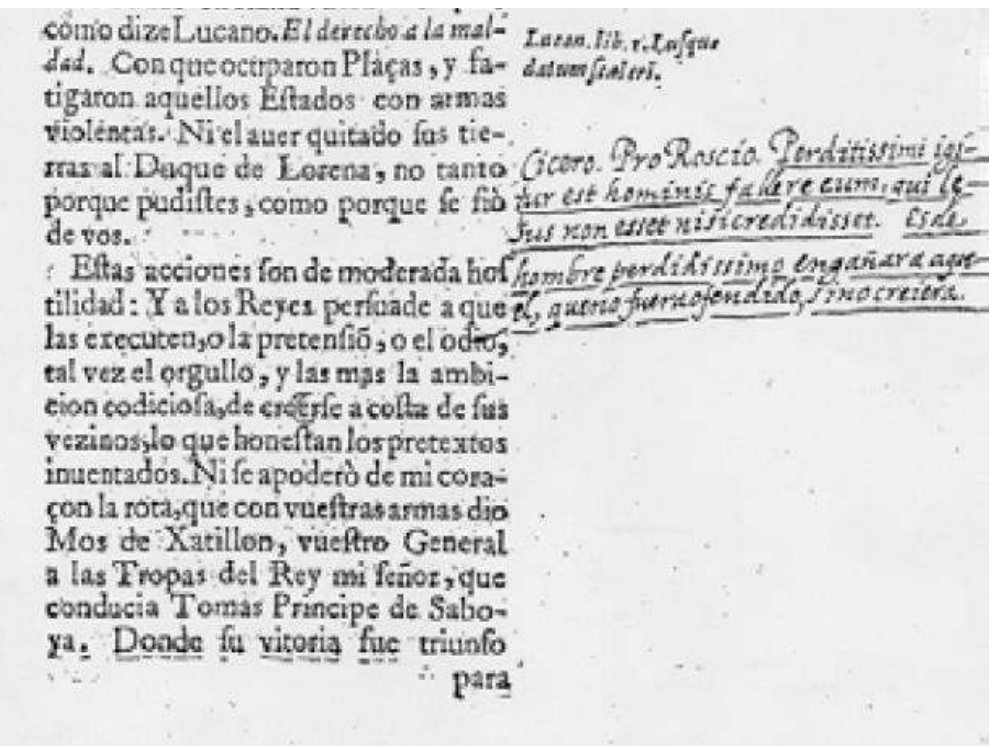

\section{Note holographe sur un imprimé de la lettre à Louis XIII ayant appartenu à Quevedo (annexe de l'article de C. Pereita Huerta).}

Le recours à cette autorité classique souligne la problématique des terres de Lorena et la douloureuse trahison d'une amitié. Le reproche argué contre la France est clair et laisse poindre, de façon plus générale, une désespérance face à la brisure des pactes et amitiés. Parallèlement sur la page de garde de l'imprimé, l'auteur a couché une longue annotation qui discrédite deux

\footnotetext{
58 JOHNSON, Carroll B., "Quevedo in Context : Personality, Society, Ideology », Mester, n² (1980), p. 3-16, affirme à cet effet que «Durante toda su vida Quevedo busca la amistad, aprobación y protección de una serie de hombres más poderosos que él ».

${ }^{59}$ Lire à ce sujet l'article-clé de Carmen PERAITA HUERTA, « Mapas de lectura, diálogos con los textos : la Carta al rey Luis XIII y las anotaciones en el ejemplar de la Utopía de Quevedo », La Perinola, 8 (2004), p. 321-341, et plus précisément les pages 330-331.

${ }^{60}$ PERAITA HUERTA, Carmen, « Mapas de lectura... », art. cit., p. 340.
} 
apologies françaises ${ }^{61}$. Cette version de la lettre reprise indique, d'après les hypothèses de Carmen Peraita Huerta $^{62}$, que Quevedo s'appliqua à remanier son texte après sa publication, soit pour contredire certains détracteurs et censeurs de sa lettre, soit pour profiler davantage d'adéquation entre cet écrit et des destinataires précis, comme Olivares ou un nombre très restreint de lecteurs issus des cercles du pouvoir - et notamment espagnols comme le suggère le contenu en castillan de ce libelle alors que bon nombre circulaient en latin ou français. ${ }^{63}$ De fait, dans un épitexte, une correspondance avec Sancho de Sandoval datée du 13 novembre 1635, l'écrivain fait mention de ce pamphlet contre la politique de Louis XIII et de son impression destinée essentiellement à la Cour espagnole et autres figures royales : «Con el portador remito a V. M. esa Carta que escribí al Rey de Francia, respondiendo a su Manifiesto, que llevaré a Beas conmigo. Es de lo de marquilla ${ }^{64}$, que imprimí para Palacio y para Flandes y Alemania a las personas reales ${ }^{65}$. Notons au passage le succès éditorial de cette lettre au monarque français qui a sûrement influencé l'attitude de l'auteur, l'incitant à un contrôle de la réception eu égard à son commanditaire d'autant que cet écrit a bénéficié de pas moins de six éditions en 1635 et une autre encore en $1636^{66}$. Quevedo - tout comme Gaspar de Guzmán, comte-duc d'Olivares - était conscient de la portée de ces libelles politiques et de la dangerosité de leur interprétation ${ }^{67}$. Le paratexte holographe de l'imprimé susmentionné tend ainsi à démontrer a posteriori de la princeps, à partir d'une réfutation de toute légitimité française in medias res (dès le seuil de l'exemplaire quévédien), une attitude proespagnole, sans ambigüité aucune, qui protège Quevedo et valorise son action dans cette propagande belligérante auprès de ces lecteurs-cibles.

Un questionnement survient à cet effet quant à la nécessité pour l'auteur de rappeler son aversion française et à propos des raisons qui ont motivé, a posteriori, de telles annotations. La «vie turbulente de Quevedo», pour faire nôtres les mots d'Astrana Marín ${ }^{68}$, est ponctuée de disgrâces et d'oppositions avec le pouvoir en place tout autant que d'adhésion plénière à l'idéologie dominante à la Cour. Et à travers ce texte renfermant une telle déférence vis-à-vis de Louis XIII et surtout une invitation à la résolution du conflit France/Espagne, il appert que la position idéologique de Quevedo semble parfois lointaine à une rédaction propagandistique empreinte d'animosité. Il est vrai que le contenu du manuscrit et de l'imprimé, éclairés par les notes additionnelles de l'écrivain, atteste une défense de l'Espagne, un inconditionnel respect de la monarchie de droit divin tout en enregistrant les soubresauts conflictuels d'États naissants. Plus

\footnotetext{
61 «Escribió en latín Mario Equicola Gentilombre Italiano, una Apología contra los maldicientes de la nación francesa. Tradújole en Francés Michel Rote, impromiose em [sic] París por Vincencio Sertenas Año 1550. Refuta ridículamente los lugares de Julio Cesar Con Tacito, Tito Livio, y Lucio Floro. Escribió Equinola de Amor, y fue hombre erudito. Escribió en latín Victor Tuartio Pro Franco Gallis Contra mendatia, imposturas, et Calumnias Joannis Meinardi Frisis, in Academia Pictaviensi leguleis. Parisiis apud Bartholomeum Macerum Anno 1611. Ni el uno, ni el otro necesita de respuesta, puesto dos sus libros son un esfuerzo infeliz del ingenio, o mandado, o vendido desearon defender a Francia, y no pueden defender su defensa. AELIVS LAMPRIDIVS. In vita Alexandri Severi. Verum Galiicane mentes, vt sese habent dure, ac retrograde, et sepe Imperatoribus graues, severitatem hominis nimiam, et longe maiorem post Heliogabalum, non tulevunt ».

62 PERAITA HUERTA, Carmen, « Mapas de lectura... », art. cit., p. 331-332.

${ }^{63}$ KAGAN, Richard L., « las "plumas teñidas" de Felipe IV : ¿periodismo o propaganda ? in La aparición del periodismo en Europa, Roger CHARTIER et Carmen ESPEJO (éds.), Madrid, Marcial Pons, 2012, p. 87-102.

${ }^{64}$ Par ailleurs est bien répertoriée l'émission de la princeps (1635, veuve de Alonso Martín) « sur papier marquilla, sans indication de libraire et sans tasa exemplaire: Biblioteca Nacional, Madrid, R. 9.329» par Jaime MOLL, "Les éditions de Quevedo dans la donation Olagüe à la bibliothèque de la Casa de Velázquez » in Mélanges de la Casa de Veláaquez, tome 16, 1980, p. 457-494, et notamment les pages 468-469.

${ }^{65}$ Citation d'un échange épistolaire de Quevedo transcrit par Mercedes SÁNCHEZ SÁNCHEZ, Cartas de Francisco de Quevedo a Sancho de Sandoval (1635-1645), Madrid, Calambur, 2009, p. 125.

${ }^{66}$ LÓPEZ ESTRADA, Francisco, « Quevedo y la Utopía... », art. cit., p. 403.

${ }^{67}$ ELLIOTT, John H. indique de fait: «El caso de la España de Olivares sugiere que los nuevos recursos propagandísticos del Estado del siglo XVII eran perfectamente susceptibles de resultar contraproducentes y de perjudicar a la misma causa para cuya promoción fueron pensados », España y su mundo 1500-1700, Madrid, Alianza Editorial, p. 203.

68 ASTRANA MARÍN, Luis, La vida turbulenta de Quevedo, Madrid, Editorial Gran Capitán, 1945.
} 
encore, l'attitude de Quevedo appelé à répondre à la déclaration de guerre, enrôlé dans une mission d'État, est surprenante car il distille, en particulier à la fin du texte, une possibilité de paix. Cette duplicité trompeuse met en lumière les contrastes d'un homme politique et écrivain accusé d'avoir ourdi des complots avec la France. Certains ont, par conséquent, émis l'hypothèse que «no está del todo descartado que el retorcido, corrosivo y amargado Quevedo viera en la Francia de Luis XIII un posible instrumento para derrocar a un ministro tiránico que estaba conduciendo al país hacia la destrucción » ${ }^{69}$. La thèse d'un rôle d'espion assigné à Quevedo n'est, d'ailleurs, aujourd'hui pas écartée ${ }^{70}$, sous-entendant qu'il aurait perçu dans la France voisine un pouvoir fort susceptible de mettre fin aux déconvenues étatiques d'une monarchie espagnole en perdition. Il faut dès lors rechercher les constantes idéologiques de cet écrit circonstanciel pour en défaire les objectifs de l'expéditeur de la lettre. Attaché à l'image d'une Espagne victorieuse, il aurait exploré les moyens de sauver une Espagne en proie à une succession monarchique défaillante car «au regard d'un Charles Quint ou d'un Philippe II, leurs successeurs font assez pâle figure $»^{71}$. Quevedo s'élèvera ainsi « contre tous et tout spécialement contre les responsables de la situation espagnole : Philippe IV et Olivares ${ }^{72}$. L'issue pacifique au contexte de 1635 aurait ainsi évité à l'Espagne d'épuiser, une nouvelle fois, ses ressources. Porte-parole de la souveraineté espagnole, il ne put récuser l'engagement de sa nation dans une telle guerre après les provocations françaises ; toutefois, cet écrit suggère trêve et apaisement. La longue paraphrase finale d'un extrait de l'Utopie agit comme un catalyseur de paix. Face aux désastres annoncés de guerres à partir de fragiles alliances politiques et de conseillers néfastes, la paix incarne la voie la plus sage. Il n'est pas anodin que le passage fasse référence au vaste et puissant royaume de France lequel « casi es mayor de lo que puede cómodamente gobernar uno ${ }^{73}$. Quevedo, qui considérait les guerres comme incontournables et nécessaires avant 1621, opéra un revirement idéologique puisqu'il prôna par la suite, à partir de l'époque de la rédaction de cette lettre, la paix ${ }^{74}$. Son avis personnel est, à cet égard, explicite dans cette même lettre à son ami et voisin, Sancho de Sandoval - écrit daté de novembre 1635 qui transforme une nouvelle fois le contenu épistolaire en véritables chroniques de l'époque - où l'auteur se réjouit d'une éventuelle pacification de la situation hispano-française : «La estafeta pasada me escribieron de todas partes muy buenas nuevas... Yo, como lo deseo, todo lo creo $»^{75}$.

\footnotetext{
${ }^{69}$ ELLIOTT, John H., El Conde-Duque de Olivares, Barcelona, Crítica, 1990, p. 544.

${ }^{70}$ On peut ainsi lire que «Quevedo coqueteó con la idea de convertirse en «agente doble » de proporcionar a los agentes de Richelieu en Madrid algunas interpretaciones y algunos datos acerca de la política española a cambio de otras informaciones que pudieran ayudarle a desacreditar la política de Olivares, la cual, según Quevedo creía, estaba llevando a España a la ruina. Todo lo cual dio armas a Olivares para conseguir la desgracia y prisión de Quevedo» (DURÁN, Manuel, Quevedo, Madrid, Edaf, 1978, p. 34). De même, Rodrigo CACHO CASAL ("Quevedo contra todos: la segunda Parte de La Politica de Dios y su contexto », Bulletin of Hispanic Studies, vol. 87, n8 (2010), p. 897-921, et notamment les pages 914-915) rappelle que les causes de son emprisonnement comportent, au regard des recherches actuelles, deux motifs probables: la rédaction de satires virulentes contre le gouvernement et le fait d'avoir pu deviser avec des délégués français.

${ }^{71}$ CANAVAGGIO, Jean, «Le temps des contradictions » in Histoire de la Littérature Espagnole, sous la direction de Jean Canavaggio, Paris, Librairie Arthème Fayard, 1993, tome I, p. 495-514.

${ }^{72}$ CACHO CASAL, Rodrigo, «Quevedo contra todos... », art. cit., p. 909. La traduction est de nous.

73 BNE, Ms. 6156, folio 53.

${ }^{74}$ Lire à ce sujet les affirmations de PÉREZ CLOTET reprises par Francisco LÓPEZ ESTRADA, " Quevedo y la Utopía... », art. cit., p. 406-407 : "Pérez Clotet distingue una evolución en el criterio de Quevedo, si primero favorable a la guerra (hacia 1621, comienzos de Felipe IV y gobierno del Conde Duque), más adelante, sobre todo cuando escribe y termina la parte II de su Política de Dios (1635), defensor de la paz. La opinión que se manifiesta a través de las notas de la Utopia es la segunda. Y éste sería el sueño secreto de muchos españoles avisados en 1635, aun contando con el prestigio de las armas en una monarquía como la española de aquella época. Quevedo escribió la Carta a Luis XIII con gran aparato literario, y me atrevo a presumir que con este escondido deseo. Parece indudable que la inclusión del trozo de la Utopia en la Carta procede de la lectura de este ejemplar de su propiedad ».

${ }^{75}$ María Soledad ARREDONDO qui cite cet extrait de la correspondance quévédienne, "Armas de papel. Quevedo y sus contemporáneos ante la guerra de Cataluña », La Perinola, 2 (1998), p. 117-150.
} 
La rédaction de la lettre à Louis XIII, ses retouches successives par le biais des marges et la correspondance quévédienne, coïncident avec la production de la seconde partie La Política de Dios qui met en avant que :

el Quevedo de 1635 se siente aún animoso, ojo avizor sobre el contorno en que vive, deseoso de que España se mantenga entera, ya en su culminación. La paz es su gran deseo. La segunda parte de la Política de Dios, terminada hacia 1635, está claramente orientada en este sentido: «De las acciones humanas ninguna [como la guerra] es tan peligrosa, ni de tanto daño, ni asistida de tan perniciosas pasiones, envidia, venganza, codicia, soberbia, locura, rabia, ignorancia: unas la ocasionan, otras la admiten... $\gg^{76}$

Des échos similaires, en faveur de la paix, constellent la lettre à Louis XIII. Le passage qui le vérifie au mieux provient de l'extrait de l'Utopie où la conclusion est sans appel : "Concluye que se trate de paz y que se asegure con firmes lazos la siempre mal segura confederación ${ }^{77}$. En effet, cette lettre semble davantage se centrer sur la réclamation de la vengeance à l'endroit de Châtillon que sur une attaque verbale censée préfigurer la guerre entre les deux nations. Quevedo indique explicitement son ennemi, cible principale, dans une note marginale du folio 52 :

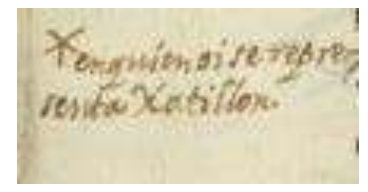

\section{Ajout marginal (Ms 6156) qui dénonce Châtillon et vient éclairer son identification dans le texte central.}

Louis XIII apparaît ainsi comme un ennemi de la cause catholique mais n'en reste pas moins un roi très chrétien, un agent divin ; c'est pourquoi Quevedo s'efforce de le persuader et de le séduire par les mots afin que cesse cette guerre, qui non seulement met en péril une Espagne harassée par les combats mais qui a surtout perdu le respect de la foi, comme en garde trace la ville de Tilermont. C'est l'imitation christique que suggère encore l'auteur en matière de conduite du Prince. Ce code ayant été enfreint, Quevedo, désormais aguerri, en 1635, devant les calamités humaines, financières et politiques que comporte chaque guerre et conscient de la puissance du rival français, répond à la déclaration de guerre avec tout le zèle patriotique qui l'anime mais laisse entrevoir le chemin de la paix $^{78}$ comme résolution aux exactions françaises et comme salut pour une Espagne fragilisée.

\section{Conclusion}

Ce texte-mosaïque, au regard de son contenu intertextuel et hétéroclite, de ses versions parfois écourtées selon les manuscrits ${ }^{79}$ mais néanmoins unitaires, et de son apparent dualisme idéologique envers la France, prend sens à la lumière des annotations marginales et de la

\footnotetext{
${ }^{76}$ LÓPEZ ESTRADA, Francisco, « Quevedo y la Utopia... », art. cit., p. 409.

${ }^{77}$ Ms 6156, folio 53.

${ }^{78}$ María Soledad ARREDONDO, «Notas para una edición...», art. cit., p. 15, mentionne, à ce sujet, l'incitation au pacifisme qui jalonne la lettre. De même, Rodrigo CACHO CASAL perçoit cette attitude quévédienne dans la deuxième partie de la Política de Dios (1636) où Quevedo s'en remet aux démarches du Pape Urbain VIII pour rétablir l'union des fils de l'Église.

${ }^{79}$ Le texte du manuscrit 6156 présente la première partie et la conclusion de la version imprimée alors que, par exemple, le manuscrit utilisé par M. S. Arredondo pour son édition comporte seulement la seconde partie de la lettre.
} 
correspondance quévédienne en marge. L'appel aux armes qui se résout en une invitation pacifique ne tend finalement qu'à préciser l'engagement de Quevedo envers un Dieu en qui il a foi pour les desseins espagnols. La problématique de la raison d'État aux mains de souverains de droit divin dont la fonction doit transcender la personne trouve théologiquement un solide creuset et une issue unanime en la figure de Dieu et de son Fils. Les notes holographes sur le texte, manuscrit et imprimé, dévoilent une position quévédienne unilatérale : la mythification patriotique de l'Espagne et la possibilité d'une résolution du conflit par le rappel du corps christique et de la prédominance de la communion catholique au-delà des frontières étatiques. Une vision quelque peu utopique en l'été 1635 car cette projection quévédienne était sans compter les prétentions de Richelieu et l'ambition d'Olivares. La future victoire espagnole de Corbie (août 1636) allait donner raison au portrait quévédien qui glorifiait les troupes espagnoles. Ces mots, "armes de papier ${ }^{80}$, ne laissèrent pas indifférent, ni le camp français ni le camp espagnol. Quevedo se consacra à cet écrit confectionné dans les convulsions de la guerre de Trente Ans en prenant soin de persuader la France, ennemi-cible, de la grandeur de l'Espagne et en soulignant les vicissitudes des soldats français. Les ratures et corrections dans la marge du manuscrit insinuent un premier jet courroucé. Toutefois, les diverses strates de notes, depuis celles du manuscrit original jusqu'à celles jonchant l'imprimé lui ayant appartenu, indiquent que l'auteur a ensuite modulé son attitude envers la nation voisine selon la double finalité mise en exergue : l'accusation acerbe contre Châtillon ainsi que la déclaration de guerre alliant belligérance et souhait de paix. De surcroit, cette évolution se décline selon le sujet visé : les ministres et conseillers du souverain français que Quevedo vilipende ou Louis XIII que l'auteur traite avec déférence. Finalement, une troisième épaisseur du texte se découvre, à partir des notes sur l'imprimé, car selon le destinataire précis de cet écrit, le favori espagnol ou les détracteurs de Quevedo, l'auteur prend soin d'argumenter sur les faiblesses françaises.

Pour nuancer les propos de Jorge Luis Borges ${ }^{81}$ qui affirmait que l'auteur laisse derrière lui deux œuvres, le texte et l'image de l'auteur, l'étude des marges de cette lettre à Louis XIII donne à voir une seule position quévédienne qui reprend, telle une mise en abyme, le centre du texte tout comme le parcours de sa vie d'auteur et d'acteur politique. Il se forgea, d'abord, une réputation acerbe et provocatrice, à l'aune de la tonalité des passages extrêmement patriotiques et blessants pour la France finalement raturés et corrigés. Ensuite, les gloses montrent une écriture canalisée et instrumentalisée à des fins idéologico-politiques: respecter le reflet divin qui s'immisce à l'intérieur de chaque souverain sans oublier pour autant de fustiger les vices français. Enfin, il contente le favori, commanditaire de cette œuvre, par des ajouts marginaux sur l'imprimé en prônant paradoxalement une possible paix avec l'ennemi, au nom de Dieu, et pour que perdure la splendeur de l'Espagne. Si le paratexte recèle une frange indécise entre le texte et le hors-texte ${ }^{82}$, les marges quévédiennes contiennent ici les volontés d'un auteur décidé à influencer le destin d'une nation à la croisée des fondements de la monarchie absolue et de la raison d'État. L'espace liminaire fait office, dans cette production circonstancielle, de ligne arbitraire décidée et dessinée par l'auteur où s'évapore la notion de cadre et de frontière, afin de rapprocher le texte des saillances du réel, à savoir son point d'origine.

Ce libelle problématise finalement le cycle de vie de cet écrivain, écartelée entre idéaux patriotiques et intérêts personnels, tout en radiographiant la relation franco-espagnole soumise à un continuel changement car: "Sale de la guerra, la paz: de la paz, la abundancia; de la abundancia, ocio; del ocio, vicio; del vicio, guerra ${ }^{83} »$.

\footnotetext{
${ }^{80}$ Nous reprenons le titre de l'article susmentionné de María Soledad ARREDONDO.

${ }^{81}$ Cité par Anne CAYUELA, Le Paratexte au Siècle d'or, op. cit., p. 155

82 GENETTE, Gérard, Seuils, op. cit., p. 8.

${ }^{83}$ Citation quévédienne extraite de Migajas sentenciosas relevée par Paloma OTAOLA GONZÁLEZ, Coordenadas filósoficas del pensamiento de Quevedo, Alicante, Editorial Club Universitario, 2004, p. 54.
} 